\title{
Velskrevet essaysamling med noen gullkorn, men kjapt lest og kjapt glemt
}

\section{Lars Petter Storm Torjussen}

Universitetet $i$ Bergen, Norge

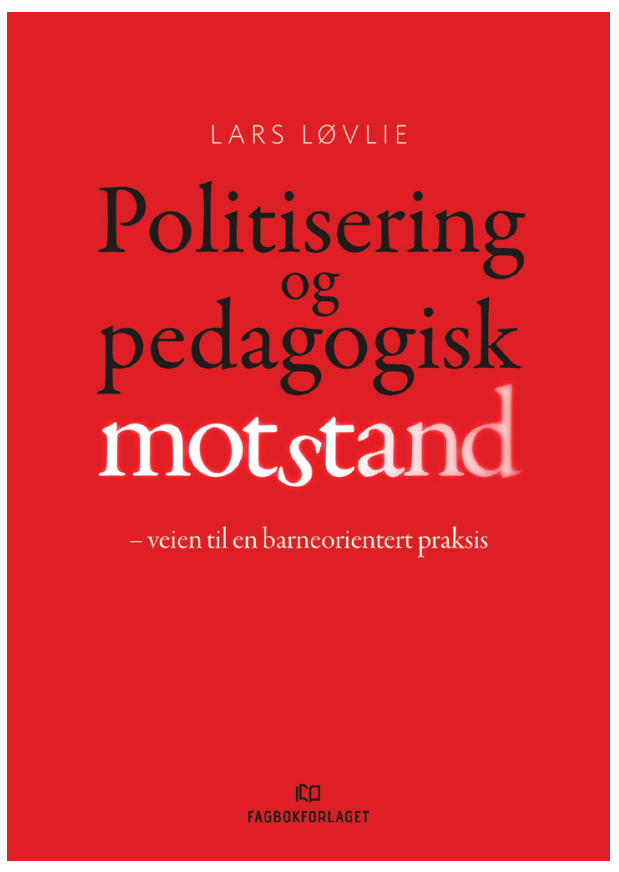

Lars Løvlie: Politisering og pedagogisk motstand. Veien til en barneorientert praksis. Fagbokforlaget, 2021, 144 sider.

Lars Løvlie tar i Politisering og pedagogisk motstand et oppgjør med hva han betegner som «moderniseringsreformen» i norsk skole og beskriver den pedagogiske motstand som er blitt giort mot denne. På baksiden av boken leser vi at moderniseringsreformen er båret frem av "villfarne politikere, byråkratisk stivsinn og nidkjære teknologer», mens motstanden på sin side består av «modige lærere, våkne foreldre og dyktige fagfolk som alle har gått til felts mot effektiviserings- og konkurransetiltakene i skolen». Men først av alt vil Løvlie tale saken for den tause majoritet i dagens norske

Korrespondanse: Lars Petter Storm Torjussen, e-post: lars.torjussen@uib.no

(C) 2021 Lars Petter Storm Torjussen. This is an Open Access article distributed under the terms of the Creative Commons Attribution 4.0 International License (https://creativecommons.org/licenses/by-nc/4.0/), allowing third parties to copy and redistribute the material in any medium or format and to remix, transform, and build upon the material for any purpose, even commercially, provided the original work is properly cited and states its license.

Citation: Lars Petter Storm Torjussen. "Velskrevet essaysamling med noen gullkorn, men kjapt lest og kjapt glemt» Nordisk tidsskrift for pedagogikk og kritikk, Vol. 7, 2021, pp. 36-40. http://dx.doi.org/10.23865/ntpk.v7.2957 
skole; nemlig barna. Det er en kort bok på vel 140 sider fordelt over fire essays som holder noenlunde samme lengde. Disse essayene kan leses separat, men henger likevel til en viss grad sammen. Essayene avsluttes med gode tips til videre litteratur.

Det første essayet, "Den uekte lodning», tar hovedsakelig for seg de endringer den norske skole har gjennomgått siden 1990-tallet, men trekker også linjer lenger tilbake i historien. Her finner vi beskrivelser av dramatikken rundt Oslo-skolen slik vi kjenner den gjennom den såkalte Malkenes-saken og bråket rundt Astrid Søgnens avgang som direktør for utdanningsetaten. Løvlie ser disse hendelsene i lys av nasjonale hendelser, men også internasjonale tendenser som OECDs makt over den norske skolen og fremveksten av den stadig mer internasjonale kunnskapsøkonomien. Det er fraværet av pedagogiske begrunnelser for disse endringene Løvlie ønsker å sette fokus på. Denne innvendingen er tett knyttet til Løvlies oppfatning av hva pedagogikk i det hele tatt er, nemlig en form for begrunnelse. ("Mest og i overveiende grad bruker jeg pedagogikk spesifikt om pedagogiske begrunnelser", s. 18.) Dette er en oppfatning som på sett og vis peker tilbake til Løvlies klassiker Det pedagogiske argument fra 1984. At de kreftene som i dag former skolen mangler en pedagogisk begrunnelse innebærer at de mangler a) historisk kunnskap, b) etiske og moralske vurderinger og c) barnefaglig kunnskap. Tittelen «Den uekte lodning» er et uttrykk som henspiller på Henrik Wergelands beskrivelse av dansketiden, der Norge bestod av en norsk og en dansk halvdel som ikke var loddet ordentlig sammen. Resultatet var at vi nordmenn ikke hadde en reell selvråderett. Våre dagers uekte lodning skal forstås som en konflikt mellom en styringsideologi og en pedagogisk kultur.

Den neste essayet er "Pietismen - en fortelling om det indre liv». Her vil Løvlie gi en kort historisk gjennomgang av «pietismens pedagogikk» og hvordan dens vekt på inderlighet og personlig opplevelse giennomsyret dens syn på oppdragelsen. Vi finner blant annet en presentasjon av August Hermann Francke (1663-1727) og hans virke i Halle. Essayet forfølger mange stier, men den viktigste grunnen til å tegne opp "pietismens pedagogikk» - som en vilje til å styre barns indre liv og seksualitet gjennom bekjennelse og gudsfrykt - synes å være å formulere en innsikt som fremdeles har pedagogisk relevans, nemlig at «indre frihet ikke lar seg realisere ved press» (s. 73).

I det tredje essayet er Løvlie på hjemmebane. I "Rousseau - det uferdiges pedagogikk» fortsetter Løvlie tematikken om det indre liv fra forrige essay, bare at hos Rousseau finner vi en behandling av det indre liv som er utpreget sekulær. Dette er tema Løvlie har behandlet flere ganger før. Hos Rousseau blir det indre liv behandlet som natur og som en læremester, ikke som en kilde til synd. Med dette blir Rousseaus store gevinst å innse at det viktigste premiss for oppdragelsen ligger hos barnet selv. Den «barnefaglige» kunnskapen Løvlie etterlyser i dag stammer derfor på sett og vis fra Rousseau. Løvlie viser til forbindelsene mellom Rousseaus biografi og hans filosofi og pedagogikk ved at Rousseaus naturforståelse og forfatterskap utvikler seg i sammenfallende faser. Her er også korte behandlinger av tema som er obligatoriske $\mathrm{i}$ enhver innføring i Rousseaus tenkning, nemlig den negative oppdragelse, 
oppdragelsens tre læremestre (naturen, tingene og menneskene) og hans begrep om perfectibilité.

Det siste essayet, «Kultur for samtalen», avrunder det hele ved å utgiøre en undersøkelse av det som kanskje er det mest underliggende og som holder det hele sammen, nemlig språket og språkets forutsetninger. I de to foregående essays fremstilles både pietismens og Rousseaus prosjekt som mislykkede. Grunnen til dette er at de begge på ulikt vis opphøyer det indre på bekostning av det ytre. Problemet med dem var at «de så ikke at relasjonen var det egentlige subjekt i deres ulike fortellinger» (s. 24). Løvlie tar i dette essayet utgangspunkt i Wilhelm von Humboldts språkfilosofi, der språk er noe mer enn meddelelse av informasjon, men snarere det som binder oss mennesker sammen med både verden og hverandre. Også dette essayet går i mange retninger, der det er fellesskapet som et språk forutsetter - og skaper - som er i fokus. Men vi finner også en behandling av "det filosofiske barnet» eller hvordan barnet og den voksne oppfatter verden forskjellig, ja nærmest en ansats til en barnets fenomenologi og et forslag til hvordan man kan løse «oppdragelsens paradoks»

Som man ser så er det mange forskjellige tematikker som tas opp her. Løvlie formulerer selv tre overgripende temaer som holder det hele sammen, nemlig politikk (med dette menes kulturkløften mellom en administrativ kultur og en pedagogisk kultur), pedagogikk som begrunnelse og oppdragelse. Det er imidlertid ikke alltid helt klart hvor den røde tråden er i essayene og hvor Løvlie vil hen med dem. For eksempel har essayene om pietismen og om Rousseau en klar rød tråd, men det er ikke helt klart hva de vil. De kan tolkes som forsøk på å vise at mennesket har et privilegert indre liv som styringssystemer ikke kan nå frem til. Dermed vil også dagens kontrollregime være mislykket, slik pietismens forsøk på å kolonisere det indre liv var mislykket. Men de kan også tolkes som at det indre liv $i k k e$ er et privilegert område, siden det er i relasjonen mellom det indre og det ytre det avgjørende pedagogiske finner sted. Det siste essayet vet på sin side hvor det vil, men har til gjengjeld en mindre klar rød tråd.

Det kan hende dette er et "problem" med selve essaysjangeren - som jo tross alt bokstavelig talt er utforskende og eksperimenterende ("essay» betyr jo "forsøk») og ikke nødvendigvis følger en stringent lineær gjennomgang. For denne boken følger på sett og vis et ideal Nietzsche setter opp ved å henvende seg til "alle og ingen». Dette er forfriskende i våre dager, all den tid bøker i dag skal ha en tydelig adressat, siden bøker jo må treffe sitt markedssegment og estimere profitten ved å kartlegge sin pensumrelevans. Etter min mening rommer pedagogikkfaget en særegen åpenhet til å uttrykke seg i mer varierte sjangre enn IMRoD-strukturen og gørrkjedelige nivå 2-tidsskrifter.

Pedagogiske grunnbegreper som oppdragelse, undervisning og dannelse betegner en profesjonalisert vitenskapelig praksis, men denne praksisen hviler uunngåelig på en allmennmenneskelig praksis, der disse grunnbegrepene også retter seg mot innhold uttrykt i folkevisdom, eksemplariske fortellinger, dikt og kunstverk. Rousseau valgte seg jo romanen som sitt fremste pedagogiske medium. I denne henseende er det oppløftende at det fremdeles finnes mennesker som tør å sprenge disse trange 
vitenskapelige rammene og tale i store ord, ja på grensen til det pompøse (jeg mener dette positivt). Løvlies bok munner ut i en konstruert dialog nærmest av platonske dimensjoner og avsluttes med et dikt.

Men dette innebærer ikke at essayet er en beleilig unnskyldning for slappheter og omtrentligheter. Det er noen slike i denne boken, for eksempel når Løvlie på side 13 fastslår at i 2016 ble det etablert et nytt bånd mellom stat og marked, uten å forklare eller begrunne dette noe nærmere. Videre finner vi at human capital-teorien fikk et oppsving i skandinavisk utdanning omkring 1970. (Ble Theodore Schulz' og Gary Beckers verker lest på 70-tallet?) Vi finner også kritikk av «ledelsestenkningen» og noen store sveip gjennom historien som kunne trengt litt mer belegg. Det er også i det hele tatt litt uklart hva Løvlie egentlig mener med «moderniseringsreformen» som var så avgjørende på 90-tallet og som har blitt «forsøkt realisert over den siste generasjon». Dette er jo et bærende premiss for hele boken. Det er nærliggende at det er innføringen av målstyring i utdanningssystemet Løvlie sikter til her, med St.meld. nr. 37 (1990-91) Om organisering og styring $i$ utdanningssektoren som nøkkeldokument. Innføringen av målstyring var et generelt styringsprinsipp som hadde konsekvenser på veldig mange områder, ikke bare i skolen. Men merkelappen klebes også til et interndokument skrevet av Clemets administrasjon som var i sirkulasjon sommeren 2002 som skisserte opp det såkalte «Moderniseringsprosjektet 2020». Litt flere begrepsforklaringer og definisjoner kunne derfor vært på sin plass i denne boken - til tross for at det er et essay.

Når det er sagt, så skriver Løvlie godt, noen ganger drivende godt. Her er noen treffende formuleringer: «... de som ventet et vaktskifte, skulle oppleve et maktskifte» (s. 14). «Det finnes mye radikalt, men intet originalt i Clemets politiske vyer» (s. 41). Løvlie vet også å spille på språkets nyanser. Det ser vi her: "Lesing er en ferdighet, men lesning med en innskutt $n$ omfatter tolkning, og det krever den enkeltes kunnskap og selvtillit» (s. 64). Det mangler heller ikke på gode observasjoner og treffende poenger. Løvlie betoner for eksempel en forskjell mellom å lytte og å høre: «Å høre hører til øret, å lytte hører til opplevelsen» (s. 126). Lytting innebærer å være stemt og involverer hele vårt vesen. Videre viser Løvlie at Rousseau - som jo regnes som selve «oppdageren» av barndommen og kanskje selve Forfaderen til pedagogikken overhodet ikke er interessert i barnet Emiles perspektiv. Jeg har selv fundert mye på Rousseau, men akkurat dette paradokset har jeg ikke tenkt noe særlig over. Spesielt likte jeg å lese beskrivelsen av barns tidsoppfattelse, som er $i$ tiden (s. 80) og som ikke enten løper etter den eller forsøker å få den til å gå fortere, slik vi voksne gjør. Der skolens tid er en kronologisk tid (khronos) er barnets tid preget av åpenhet og «et øyeblikk som gripes» (kairos) (s. 81).

Dette er en bok som stiller grunnleggende spørsmål og inviterer til debatt. Dessverre er kanskje ikke debatten den inviterer til så veldig interessant. Med dette vil jeg avslutningsvis spille ballen over til Løvlies banehalvdel - den pedagogiske filosofien som tar opp hva pedagogikk i det hele tatt er og hvilke oppgaver den har - og utfordre noen av premissene som skaper selve grunnfortellingen i denne boken. 


\section{P. S. Torjussen}

Det første premisset er at politikken spiller rollen som bad guy og pedagogikken rollen som good guy. Dette premisset ligger også til grunn for tittelen til boken (man har politikken på den ene siden og pedagogikken, forstått som motstand, på den andre). Vi finner også dette premisset til stede i analogien om den uekte lodning: Da danskene forsvant fikk nordmennene endelig råderett og ble herrer i eget hus. Analogien inviterer dermed til en oppfatning at hvis politikken på lignende måte forsvinner, så vil pedagogikken (igjen?) få råderett, og skolen får sin rettmessige konge. Etter min mening er motsetningen mellom «politikken» og "pedagogikken» både kunstig og unyansert, og gjør at pedagogikken blir for uskyldig fremstilt sammenlignet med politikken. Jeg følger Løvlie et stykke på vei at pedagogikk innebærer motstand og andre verdsettinger og legitimeringer enn hva politikken ønsker å oppnå. Men det blir underbelyst at pedagogikken også har islett av hva Slagstad kaller en styringsvitenskap. Hvis vi ser på den pedagogiske faghistorien ser vi nemlig at det ikke nødvendigvis er en konflikt mellom det «barnefaglige», som Løvlie etterlyser, og hangen til testing og måling. Hos for eksempel Helga Eng går respekten for barnets verden og lekens betydning hånd i hånd med psykometri og intelligenstesting. En mer interessant debatt ville vært å diskutere den kontinuitet som finnes mellom den kompetansedreiningen og det testregimet vi har i dag og den barnesentrerte reformpedagogikken slik den har utviklet seg gjennom det 20. århundret.

Det andre premisset jeg vil utfordre et at pedagogikken fremstilles nesten utelukkende som «barnefaglig» eller barnesentrert. Jeg er enig i at pedagogikken taler barnets sak og på denne måten er barnets advokat, men pedagogikken er da vitterlig også den rådende kulturs og den forrige generasjons talsmann. Ja, vi kan si at pedagogikken står i en særegen posisjon mellom barnet og samfunnet. Dermed blir det ikke så enkelt å trekke et markant skille mellom den pedagogiske kultur og politikkens styringsideologi som det blir gjort her. Debatten boken inviterer til er derfor ikke så veldig interessant, siden den handler om en snill og selvgod pedagogikk som forsvarer barna mot de skitne samfunnskreftene og uvettige politikere og teknokrater. Ikke misforstå. Jeg deler Løvlies bekymringer og behov for motstand, men etterlyser et mer nyansert syn på pedagogikkens oppgaver og rolle i denne motstanden.

Til tross for dette er boken likevel vel verd å lese. Men godt språk, gode observasjoner og noen gullkorn til tross: Dette er en bok som fungerer best som en innføring. Til bruk utover dette er den kjapt lest og kjapt glemt. 